\title{
Child Abuse and Neglect and Subclinical Cardiovascular Disease among Midlife Women
}

\author{
Rebecca C. Thurston, $\mathrm{PhD}^{1,2}$, Yuefang Chang, $\mathrm{PhD}^{3}$, Emma Barinas-Mitchell, $\mathrm{PhD}^{2}$, Roland \\ von Känel, MD ${ }^{4}$, J. Richard Jennings, PhD $^{1}$, Nanette Santoro, MD $^{5}$, Doug P. Landsittel, \\ $\mathrm{PhD}^{6}$, and Karen A. Matthews, $\mathrm{PhD}^{1,2}$
}

${ }^{1}$ Department of Psychiatry, University of Pittsburgh School of Medicine, Pittsburgh, PA, USA ${ }^{2}$ Department of Epidemiology, University of Pittsburgh Graduate School of Public Health, Pittsburgh, PA, USA ${ }^{3}$ Department of Neurosurgery, University of Pittsburgh School of Medicine, Pittsburgh, PA, USA ${ }^{4}$ Department of Neurology, Inselspital, Bern University Hospital, and University of Bern, Bern, Switzerland ${ }^{5}$ Department of Obstetrics and Gynecology, University of Colorado School of Medicine, Denver, CO, USA ${ }^{6}$ Department of Medicine, University of Pittsburgh School of Medicine, Pittsburgh, PA, USA

\begin{abstract}
Objective-A childhood history of abuse or neglect may be associated with elevated adult cardiovascular disease (CVD) risk. No studies have examined associations between child abuse/ neglect and subclinical CVD using a validated measure of abuse and neglect. We hypothesized that midlife women with a childhood abuse or neglect history would have increased subclinical CVD beyond standard CVD risk factors. We tested moderation of associations by sleep, hot flashes, and race/ethnicity.
\end{abstract}

Methods—295 midlife women completed the Child Trauma Questionnaire, physiologic hot flash and actigraphic sleep monitoring, blood draw, and carotid ultrasound (intima media thickness, IMT; plaque). Relations between abuse/neglect and outcomes were tested in linear regression models adjusting for demographic, psychosocial, and CVD risk factors. Interactions with sleep, hot flashes, and race/ethnicity were tested.

Results-45\% of women reported a history of child abuse or neglect. Women with any child abuse or neglect had higher IMT $[\mathrm{b}(\mathrm{SE})=.039(.011), \mathrm{p}<.01]$ and carotid plaque $[\mathrm{OR}(95 \% \mathrm{CI}=1.95$ (1.15-3.33), p<.05] than non-abused/neglected women. Further, physical abuse, emotional abuse, or emotional neglect were associated with higher subclinical CVD. Sexual abuse was associated with higher IMT among nonwhite women. Interactions with sleep time and sleep hot flashes (p values $<.05$ ) indicated that higher subclinical CVD with an abuse/neglect history was observed primarily among women sleeping $<6$ hours/night or with sleep hot flashes.

Corresponding Author: Rebecca C. Thurston; 3811 O’Hara St, Pittsburgh, PA 15213; 412-648-9087; 412-648-7160 (fax) thurstonrc@upmc.edu.

Conflicts of Interest

For the remaining authors none were declared. 
Conclusions-A history of child abuse or neglect is associated with higher subclinical CVD in women, particularly when paired with short sleep or hot flashes. Findings underscore the importance of childhood adversity in midlife women's CVD risk.

\section{Keywords}

Atherosclerosis; Cardiovascular Disease; Abuse; Violence; Sex; Women

\section{Introduction}

Cardiovascular disease (CVD) is the leading cause of death among women (1). Psychosocial factors are increasingly appreciated as important for the development of CVD (2). One particularly toxic social exposure is childhood abuse, the prevalence of which is estimated at $15-27 \%$ among US women $(3,4)$.

A history of abuse is a potent risk factor for poor mental health outcomes (5). However, a link between an abuse history and chronic disease outcomes, including CVD, is less wellestablished. Emerging data link a child abuse history to adult CVD risk $(6,7)$. However, these studies quantified CVD largely via self-reported events, which are subject to potential biases in presentation, detection, and reporting (8).

Subclinical CVD indices are useful in investigating psychosocial exposures and CVD risk among midlife women. For these indices, imaging modalities such as ultrasound are used to quantify the development of atherosclerosis before clinical disease is present, and have the advantage of avoiding biases in event reporting and detection. One such measure is carotid intima media thickness (IMT), a well-validated and highly reproducible index significantly associated with later CVD $(9,10)$. Subclinical CVD indices are particularly useful for investigating CVD risk among midlife women, among whom clinical CVD events are relatively rare (11).

We previously found that midlife women participating in the Study of Women Across the Nation (SWAN) who reported having a history of childhood sexual abuse had higher carotid IMT (12). Although a critical first step, data were limited, and therefore findings should be regarded as preliminary. Only physical and sexual abuse data were available, and measured via two questions only. Women self-labeled abuse, and therefore the experiences that constituted abuse were not standardized across women. Emotional abuse or neglect, key childhood adversities, were not assessed. In short, investigation of relations between abuse and neglect and subclinical CVD with validated, multidimensional measure of childhood abuse/neglect is now needed. Further, not all women exposed to abuse develop CVD. Thus, investigation of factors that may modify, or buffer against the cardiovascular impact of abuse is needed.

In a newly recruited cohort of 300 nonsmoking midlife women free of clinical CVD (MsHeart), we tested whether a history of child abuse or neglect was associated with higher carotid subclinical CVD, as measured by carotid IMT and carotid plaque. Improving upon prior work, we measured abuse/neglect via a validated multidimensional scale. We also considered types of abuse and neglect in relation to subclinical CVD and examined 
associations adjusting for a range of CVD risk factors. We further considered a moderating role of sleep and hot flashes in these associations, as poor sleep and hot flashes are common among midlife women $(13,14)$, have been associated with abuse $(15,16)$ and CVD risk $(17$, 18 ) and may exacerbate any cardiovascular sequelae of abuse. Finally, we tested racial/ ethnic differences in abuse-IMT associations.

\section{Methods}

\section{Design and Procedures}

The MsHeart Study, conducted between January 2012 through May 2015, included 304 women aged 40-60 recruited from the community via advertisements, mailings, fliers, and message boards. Participants underwent physical measurements; ambulatory physiologic hot flash, electrocardiogram, and actigraphic sleep monitoring; a blood draw; and a carotid artery ultrasound for assessment of subclinical CVD. Procedures were approved by the University of Pittsburgh Institutional Review Board. Participants provided written informed consent.

\section{Study Sample}

The study sample was comprised of 304 late perimenopausal and postmenopausal (19) nonsmoking women ages 40-60. By design, half of the women reported daily hot flashes/ night sweats, and half reported no hot flashes/night sweats (past three months). Exclusion criteria included hysterectomy and/or bilateral oophorectomy; a reported history of heart disease, stroke, arrhythmia, gynecological cancer, pheochromocytoma, pancreatic tumor, kidney failure, seizures, Parkinson's disease, or Raynaud's phenomenon; current pregnancy; or having used the following medications within the past 3 months: estrogen or progesterone, selective estrogen receptor modulators, selective serotonin reuptake inhibitors, serotonin norepinephrine reuptake inhibitors, gabapentin, insulin, beta-blockers, calcium channel blockers, alpha-2 adrenergic agonists, or other antiarrhythmic agents. Women who had undergone uterine ablation, endarterectomy, or lymph node removal or who were undergoing chemotherapy, hemodialysis, or peritoneal dialysis were excluded.

Of the 304 women, four women were excluded from the current analysis due to missing carotid data (equipment failure: $\mathrm{N}=3$; poor image quality: $\mathrm{N}=1$ ), five women due to missing covariate data [Homeostatic Model Assessment (HOMA): $\mathrm{N}=3$, low density lipoprotein cholesterol (LDL-C): $\mathrm{N}=2$ ], and up to nine women due to missing abuse/neglect data depending upon the subscale (physical abuse: $\mathrm{N}=2$, emotional abuse $\mathrm{N}=3$, sexual abuse: $\mathrm{N}=9$, physical neglect $\mathrm{N}=1$; emotional neglect $\mathrm{N}=3$ ). Excluded women had higher triglycerides than included women ( $\mathrm{p}<.05$ ). Final sample sizes ranged from $\mathrm{N}=286$ (sexual abuse) to $\mathrm{N}=295$ (any abuse/neglect). Five additional women missing sleep actigraphy data were excluded from secondary analyses of sleep.

\section{Measures}

Child Abuse and Neglect-The 28-item Child Trauma Questionnaire (CTQ) is a validated measure of child abuse and neglect experienced at or before age 18 (20). It has five subscales (emotional abuse, physical abuse, sexual abuse, emotional neglect, physical 
neglect). The CTQ has strong test-retest reliability (0.79-0.86), internal consistency ( $a=.75-$. 94 across subscales), and convergent validity $(20,21)$. An example question is "I got hit or beaten so badly that it was noticed by someone like a teacher, neighbor, or doctor," rated from 1 (never) to 5 (very often true). A minimization/denial subscale is also included to detect positive impression management and underreporting. The CTQ and its subscales were considered continuous scales as well as dichotomized according to clinical cutpoints (if scoring at or above threshold, individual is classified as positive: emotional abuse $=10$, physical abuse $=8$, sexual abuse $=8$, emotional neglect $=15$, physical neglect $=8$; any abuse or neglect=scoring at or above the clinical threshold on any one subscale). CTQ clinical cutpoints have sensitivity and specificity $\searrow 0.85$ relative to clinical interview (21).

Carotid Ultrasound-Certified sonographers at University of Pittsburgh's Ultrasound Research Laboratory (URL) obtained bilateral carotid images via B-mode ultrasound using a Sonoline Antares (Siemens, Malvern, PA) high resolution duplex scanner with a VF10-5 transducer. Digitized images were obtained at end-diastole from eight locations (four locations each from the left and right carotid arteries): the near and far walls of the distal common carotid artery (CCA; $1 \mathrm{~cm}$ proximal to the carotid bulb), the far walls of the carotid bulb (the point in which the near and far walls of the common carotid are no longer parallel, extending to the flow divider), and the internal carotid artery (from the flow divider to $1 \mathrm{~cm}$ distal to this point). Values were obtained by electronically tracing the lumen-intima interface and the media-adventitia interface across a 1-cm segment for each of these eight segments; one measurement was generated for each pixel over the area for a total of $\sim 140$ measures per segment. Values for these measures were recorded for each of the eight locations and the mean of the average or maximal readings across these locations comprised average and maximal IMT, respectively. Images were read at the University of Pittsburgh URL using semi-automated reading software (22). Reproducibility of IMT measures was excellent [intraclass correlation coefficient between sonographers $\searrow 0.87$, between readers $=0.92]$. Adventitial diameter $(\mathrm{AD})$ was measured directly as the distance from the adventitial-medial interface on the near wall to the medial-adventitial interface on the far wall at end-diastole. Sonographers measured the presence and extent of plaque in five segments of the left and right carotid artery (distal and proximal common carotid artery, carotid bulb, proximal internal and external carotid arteries) (23). Plaque was defined as a distinct area protruding into the vessel lumen $\geq 50 \%$ thicker than the adjacent IMT. The degree of plaque was graded as 0 (no plaque) to 3 (plaque covering $\geq 50 \%$ of vessel diameter). Grades from all segments of the left and right carotid artery were summed to a plaque index (24). Plaque assessment agreement between sonographers was high $(\kappa=0.78)$. Plaque was categorized as any/none for analysis.

\section{Sleep and hot flashes}

Sleep was assessed over three days via actigraphy (25). Data were collected with an Actiwatch 2 (Respironics, Inc., Murrysville, PA) in 1-min epochs and analyzed with Philips Actiware v6.0.0 software. Bedtime (time tried to go to sleep) and rise time (final wake time) were collected via sleep diary. Total sleep time [time in bed-sleep onset latency-wake after sleep onset] was of primary interest given its association with CVD risk (18). Wake after sleep onset (minutes of wakefulness between sleep onset time and final wake time) and sleep 
efficiency $(100 \% *$ total sleep time/time in bed) were also considered. Participants completed the Berlin Questionnaire, a validated self-report inventory assessing sleep apnea (26).

Hot flashes were quantified via physiologic hot flash monitoring (sternal skin conductance monitoring (27-29)) conducted over 24 hours. Skin conductance was sampled from the sternum at $1 \mathrm{~Hz}$ from two $\mathrm{Ag}-\mathrm{Ag} \mathrm{Cl}$ electrodes via the VU-AMS monitor (VU University Amsterdam, Netherlands). Hot flashes were scored via UFI software (DPSv3.7; Morro Bay, CA) in accordance with standard methods with established validity $(27,29)$, including in our laboratories (28). Hot flashes were classified as sleep/wake by sleep diary and actigraphy. To account for variations in monitoring duration, hot flash rates were calculated as hot flash number/monitoring time, with rates standardized to a 17 -hour wake and 7-hour sleep time for ease of interpretation.

\section{Covariates}

Demographics, medical and psychiatric history, and health behaviors were assessed by questionnaire. Height and weight were measured via a fixed stadiometer and a balance beam scale. Body mass index (BMI) was calculated $\left(\mathrm{kg} / \mathrm{m}^{2}\right)$. Blood pressure (BP) was measured via a Dinamap device after a seated, 10-min rest (final $\mathrm{BP}=$ mean of second and third measurements). Menopause status was obtained from reported menstrual bleeding, categorized as perimenopausal ( $>2-<12$ months amenorrhea), or postmenopausal ( $>12$ months amenorrhea) (19). Women were asked via questionnaire to report their race/ethnicity, their highest education level achieved, and whether they were a shift worker. They were interviewed about medications they were using (classified for the present analysis as for BPlowering, lipid-lowering, diabetes, depression, anxiety, or for sleep; each a separate dichotomous variable). Depressive symptoms were assessed by the Center for Epidemiologic Studies Depression scale (30) and anxiety via the State Trait Anxiety Inventory (31). Phlebotomy was performed after a 12-hr fast. Glucose, total cholesterol, triglycerides, and high density lipoprotein cholesterol (HDL) were measured enzymatically (Vital Diagnostics, Lincoln, RI), and LDL-C was calculated (32). Insulin was measured via radioimmunoassay, and HOMA, reflecting insulin resistance, was calculated (33).

\section{Additional measures}

High frequency heart rate variability (HF-HRV) was calculated via standard methods (34) from electrocardiograph sampled over 24 hours via the VU-AMS via three $\mathrm{Ag} / \mathrm{Ag} \mathrm{Cl}$ electrodes in a standard 3-lead configuration. Each $\mathrm{R}$ wave marker was assessed for artifacts by an artifact detection algorithm (VU-AMS.5fs software) and verified by trained coders. Estimates of HRV were conducted using VU-AMS software. Minutes with $\geq 10 \%$ ectopic beats were eliminated. The interbeat interval event series was resampled at $4 \mathrm{~Hz}$ excluding artifactual beats, interpolated, and detrended (convoluted with a smoothness prior matrix) to yield a stationary signal on which a discrete Fourier analysis was performed. High frequency band cutoffs were $0.15-0.40 \mathrm{~Hz}$.

C-reactive protein (CRP) was measured using a high sensitivity reagent set (Beckman Coulter, Brea, CA), interleukin-6 (IL-6) with an R\&D Systems (Minneapolis, MN) high 
sensitivity ELISA, and Fibrinogen activity via a modified Clauss method and Siemens (Newark, DE) Multifibren U reagent. Factor VII clotting activity (FVIIc) was assessed via standard clotting methods using Siemens Innovin thromboplastin reagent with FVII deficient plasma (HRF, Raleigh, NC), Von Willebrand factor antigen using Diagnostica Stago's (Asnieres sur Seine, France) STA-Liatest reagent, and quantitative D-dimer using Diagnostica Stago's (Asnières, France) Asserachrom assay.

\section{Data analysis}

HOMA, triglycerides, CRP, IL6, HF-HRV values were natural log transformed, and CTQ scores transformed as 1-1/CTQ for analysis. Differences between participants by included/ excluded status or by abuse/neglect exposure were tested using t-tests, Wilcoxon rank sum tests, and chi-square tests. Associations between abuse/neglect and outcomes were evaluated using linear and logistic regression, with each abuse/neglect exposure considered separately. The CTQ and its subscales were treated both as continuous variables (with effect sizes corresponding to. 05 unit increases of the transformed scale, or approximately $1 \mathrm{SD}$ increases) and as categorical variables classified according to clinical cutpoints (for ease of interpretation). Covariates were selected based upon their prior documented associations with IMT and associations with the outcome at $\mathrm{p}<.10$. Medication variables were forced into models. Additional covariates were added individually to multivariable models in secondary models. Interactions were tested by cross product terms in models. Analyses were performed with SAS v9.2 (Cary, NC). Models were two-sided, $a=0.05$.

\section{Results}

Participants were on average 54 years old, overweight, and normotensive (Table 1). The prevalence of abuse or neglect ranged from $14 \%$ (sexual abuse) to $24 \%$ (emotional abuse), with $45 \%$ of women reporting some form of abuse or neglect (Table 2). Nonwhite women were more likely to report any abuse/neglect (nonwhite: $56 \%$, white: $41 \%, \mathrm{p}=.015$ ), physical abuse (nonwhite: $29 \%$, white: 17\%, p=.019), and physical neglect (nonwhite: $29 \%$, white: $17 \%, \mathrm{p}=.022)$ than were white women.

A history of any abuse or neglect was associated with higher carotid mean IMT, maximal IMT, and carotid plaque in multivariable models (Table 3, Figure 1). In considering subscales, we found a history of physical abuse was associated with higher IMT and plaque, and emotional abuse or emotional neglect was associated with higher IMT. Associations persisted adjusting for demographics and CVD risk factors.

We considered several modifiers of associations between abuse or neglect and IMT. Sleep time significantly modified relations between any abuse/neglect ( $\mathrm{p}=.047)$, physical abuse $(\mathrm{p}=.010)$, or emotional abuse ( $\mathrm{p}=.046)$ and IMT in multivariable models, such that relations between abuse/neglect and IMT were primarily observed among women sleeping < 6 hours/ night (median sleep time; Figure 2). Similarly, associations between any abuse/neglect and plaque were observed among women sleeping $<6$ hours/night [OR $(95 \% \mathrm{CI})=2.57(1.07-$ $6.13), \mathrm{p}=.034 ; \succeq 6$ hours/night: OR $(95 \% \mathrm{CI})=1.41(.66-3.00), \mathrm{p}=\mathrm{ns}$; interaction $\mathrm{p}=.032]$. No interactions were observed for other sleep characteristics. Sleep hot flashes also modified relations between physical abuse $(\mathrm{p}=.007)$ or emotional neglect $(\mathrm{p}=.011)$ and IMT, with 
relations observed among women with sleep hot flashes (Figure 3). Finally, race/ethnicity modified the sexual abuse score ( $\mathrm{p}=.019)$ and any abuse/neglect $(\mathrm{p}=.046)$ in relation to IMT, with relations stronger for nonwhite women [sexual abuse, per SD increase in transformed scale score, nonwhite: $\mathrm{b}(\mathrm{SE})=.03$ (.01), $\mathrm{p}=.035$; white: $\mathrm{b}(\mathrm{SE})=-.009$ (.008), $\mathrm{p}=.245$; any abuse/neglect, nonwhite: $\mathrm{b}(\mathrm{SE})=.08$ (.02), $\mathrm{p}=.001$; white: $\mathrm{b}(\mathrm{SE})=.02(.01), \mathrm{p}=.113$ ].

We conducted several secondary analyses. First, we considered the secondary outcome of carotid adventitial diameter (AD), a potential indicator of vascular remodeling; the presence of abuse or neglect (but not subscales) was associated with higher $\mathrm{AD}[\mathrm{b}(\mathrm{SE})=.23(.07), \mathrm{p}=$. 001, per SD increase in transformed scale score, multivariable]. Second, we considered sleep hot flashes, sleep time, depressive symptoms, state and trait anxiety, apnea symptoms, inflammatory and hemostatic markers (CRP, IL-6, D-dimer, FVIIc, Von Willebrand factor, Fibrinogen), and sleep and wake HF-HRV as additional covariates in abuse/neglect-IMT relations, and conclusions were unchanged (data not shown). Third, we considered that short sleep may mark women with greater abuse, yet sleep time was not related to abuse/neglect when considered categorically or continuously (data not shown). Fourth, given that sleep hot flashes can disturb sleep, we examined models including both sleep hot flashes and sleep time interactions with physical abuse and IMT; both sleep time and sleep hot flashes independently modified abuse-IMT associations (data not shown). Fifth, we examined associations excluding shiftworkers $(\mathrm{N}=18)$ or women reporting a history of post-traumatic stress disorder ( $\mathrm{N}=7$ ), and findings were unchanged (data not shown). Sixth, we considered the possibility that the relation between abuse/neglect and IMT would be modified by educational attainment and tested interactions between education and abuse/neglect total scale score and subscores; none of the interactions were statistically significant (p's >.24). Finally, we found higher scores on the minimization/denial CTQ subscale associated with higher IMT [b (SE)=.009 (.004), p=.016, per SD increase in transformed scale score multivariable models], indicating that the tendency to under-report or minimize childhood adversity was associated with higher IMT.

\section{Discussion}

A childhood history of abuse or neglect was associated with higher subclinical CVD as assessed by carotid IMT and plaque among midlife women. Associations were not accounted for by standard or novel CVD risk factors, demographics, medications, or depressive or anxious symptoms. Associations varied as a function of sleep time and to a lesser extent sleep hot flashes, such that relations between abuse and subclinical CVD were most pronounced for women sleeping less than six hours or with sleep hot flashes. Finally, a history of sexual abuse was associated with higher IMT among non-white women.

Associations between abuse and subclinical CVD were most consistent for any abuse or neglect as well as for physical abuse, emotional abuse, and emotional neglect. Sexual abuse was associated with IMT for non-white women only. Our prior work in a different cohort of women (SWAN) in which we examined associations between child physical or sexual abuse and IMT showed associations solely for sexual abuse, with no interactions by race/ethnicity (12). Notably, sexual abuse was somewhat less common in the present sample than in our prior work; only fourteen white women had a history of sexual abuse. Further, our prior 
work only used two questions to assess abuse, did not assess emotional abuse, and did not assess neglect. Here we used a far more detailed, validated scale measuring multiple dimensions of abuse and neglect. Abuse was operationalized with specific behaviors, standardizing across women what exposures were considered abuse. With this much more rigorous measure of abuse and neglect, we found a history of abuse and neglect associated with higher subclinical CVD.

Factors that exacerbate or buffer against the cardiovascular sequelae of abuse are rarely considered. We found relations between abuse or neglect and subclinical CVD varying by sleep time and to a lesser extent sleep hot flashes (both of which were measured physiologically). Associations between abuse and subclinical CVD were largely observed for women sleeping less than six hours/night or with sleep hot flashes. Short sleep is common among midlife women (14); about half of the women here slept less than six hours/ night. Hot flashes are also prevalent at midlife (13). Notably, inclusion of sleep time and sleep hot flashes as covariates had little effect, suggesting that these factors moderate, rather than mediate, abuse-subclinical CVD associations. Further, sleep time and sleep hot flashes independently modified abuse-IMT relations. Short sleep and hot flashes have been associated with CVD risk $(17,18)$, suggesting that these menopausal symptoms may act synergistically with childhood exposures to affect women's CVD risk. Another interpretation of these findings is that adequate sleep may help buffer against the negative cardiovascular sequelae of childhood abuse.

The pathways linking child abuse to subclinical CVD require elucidation. Women with an abuse history or other adverse psychosocial exposures often have a poorer CVD risk factor profile (35-38), yet associations here were not explained by risk factors. Depression and anxiety are typical sequelae of abuse and linked with CVD risk $(2,38)$, yet did not explain observed relations. Childhood adversity has been linked to inflammatory dysfunction ( 38 , 39), hypothalamic pituitary adrenal (HPA) axis dysfunction $(38,40)$, and altered adrenergic function (41); with the exception of the HPA axis which should be considered in future work, many of these pathways were considered here and did not explain associations. Further, our findings underscore the importance of nocturnal physiology in abuse-CVD risk associations.

This investigation had limitations. Child abuse/neglect were assessed via retrospective report, which has known limitations, particularly underreporting (42). In fact, women who tended to minimize childhood adversity had higher IMT, indicating that rates of and relations between abuse/neglect and IMT may have been underestimated. Although a wide range of midlife risk factors were covaried, childhood CVD risk factors were not available. Further, power for analyses of sexual abuse and select interactions may have been limited due to small cell sizes. Although women were queried about a history of post-traumatic stress disorder (PTSD), and results persisted excluding these women, PTSD was not diagnosed via clinical interview here and further work should continue to investigate the role of PTSD in these associations $(43,44)$. Future work should also investigate adaptive psychological or personality factors that may moderate the impact of adversity on health. (45) The racial/ethnic diversity of the sample was somewhat limited and men were excluded, limiting generalizability of these findings to these groups. 
This investigation had several major strengths. Child abuse and neglect was assessed with a widely-used validated scale. The outcome was subclinical CVD, a measure associated with later events and preferred over self-reported CVD outcomes typically employed in this literature. Demographic and CVD risk factors were rigorously considered. Finally, key modifiers of abuse-subclinical CVD relations were tested. Both sleep and hot flashes were measured physiologically, important as they occur nocturnally when reporting is a particular challenge.

\section{Conclusions}

A history of child abuse or neglect was associated with greater evidence of subclinical CVD during adulthood. These associations were not accounted for by a range of potential confounders. Further, the negative cardiovascular impact of abuse was observed primarily among women who were short sleepers, experiencing overnight hot flashes, or who were nonwhite. Findings point to a potential role of adequate sleep duration in buffering against the negative cardiovascular sequelae of an abusive childhood. Finally, our findings underscore the importance of a lifespan perspective, considering childhood adversities in conjunction with midlife symptoms when considering women's CVD risk.

\section{Supplementary Material}

Refer to Web version on PubMed Central for supplementary material.

\section{Acknowledgments}

Sources of Funding

N Santoro has received grant support from Bayer Healthcare and owns stock options in Menogenix.

This work was supported by the National Institutes of Health, National Heart Lung and Blood Institute (R01HL105647, K24123565 to Thurston) and the University of Pittsburgh Clinical and Translational Science Institute (NIH UL1TR000005).

\section{Abbreviations}

$\begin{array}{ll}\text { AD } & \text { adventitial diameter } \\ \text { BMI } & \text { Body Mass Index } \\ \text { BP } & \text { blood pressure } \\ \text { CCA } & \text { common carotid artery } \\ \text { CRP } & \text { C-reactive protein } \\ \text { CTQ } & \text { Child Trauma Questionnaire } \\ \text { CVD } & \text { cardiovascular disease } \\ \text { FVIIc } & \text { Factor VII clotting activity } \\ \text { HDL } & \text { high density lipoprotein cholesterol }\end{array}$




$\begin{array}{ll}\text { HF-HRV } & \text { high frequency heart rate variability } \\ \text { HOMA } & \text { Homeostatic Model Assessment } \\ \text { IL-6 } & \text { interleukin-6 } \\ \text { IMT } & \text { intima media thickness } \\ \text { LDL-C } & \text { low density lipoprotein cholesterol } \\ \text { PTSD } & \text { post-traumatic stress disorder } \\ \text { URL } & \text { Ultrasound Research Laboratory }\end{array}$

\section{References}

1. Go AS, Mozaffarian D, Roger VL, Benjamin EJ, Berry JD, Borden WB, Bravata DM, Dai S, Ford ES, Fox CS, Franco S, Fullerton HJ, Gillespie C, Hailpern SM, Heit JA, Howard VJ, Huffman MD, Kissela BM, Kittner SJ, Lackland DT, Lichtman JH, Lisabeth LD, Magid D, Marcus GM, Marelli A, Matchar DB, McGuire DK, Mohler ER, Moy CS, Mussolino ME, Nichol G, Paynter NP, Schreiner PJ, Sorlie PD, Stein J, Turan TN, Virani SS, Wong ND, Woo D, Turner MB. Heart disease and stroke statistics-2013 update: A report from the american heart association. Circulation. 2013; 127:e6-e245. [PubMed: 23239837]

2. Rozanski A, Blumenthal JA, Davidson KW, Saab PG, Kubzansky L. The epidemiology, pathophysiology, and management of psychosocial risk factors in cardiac practice: The emerging field of behavioral cardiology. J Am Coll Cardiol. 2005; 45:637-51. [PubMed: 15734605]

3. Adverse childhood experiences reported by adults, five states, 2009. 2010

4. Office GP. , editor. Child maltreatment 2013. Washington DC: US Department of Health and Human Services, Administration on Children, Youth, and Families; 2015.

5. Kessler RC, McLaughlin KA, Green JG, Gruber MJ, Sampson NA, Zaslavsky AM, Aguilar-Gaxiola S, Alhamzawi AO, Alonso J, Angermeyer M, Benjet C, Bromet E, Chatterji S, de Girolamo G, Demyttenaere K, Fayyad J, Florescu S, Gal G, Gureje O, Haro JM, Hu CY, Karam EG, Kawakami N, Lee S, Lepine JP, Ormel J, Posada-Villa J, Sagar R, Tsang A, Ustun TB, Vassilev S, Viana MC, Williams DR. Childhood adversities and adult psychopathology in the who world mental health surveys. Br J Psychiatry. 2010; 197:378-85. [PubMed: 21037215]

6. Wegman HL, Stetler C. A meta-analytic review of the effects of childhood abuse on medical outcomes in adulthood. Psychosom Med. 2009; 71:805-12. [PubMed: 19779142]

7. Scott KM, Von Korff M, Angermeyer MC, Benjet C, Bruffaerts R, de Girolamo G, Haro JM, Lepine JP, Ormel J, Posada-Villa J, Tachimori H, Kessler RC. Association of childhood adversities and early-onset mental disorders with adult-onset chronic physical conditions. Arch Gen Psychiatry. 2011; 68:838-44. [PubMed: 21810647]

8. Lillie-Blanton, M., Rushing, O., Ruiz, S., Mayberry, R., Boone, L. Racial/ethnic differences in cardiac care: The weight of the evidence. Menlo Park, California: The Henry J. Kaiser Family Foundation and American College of Cardiology; 2002.

9. Stein JH, Korcarz CE, Hurst RT, Lonn E, Kendall CB, Mohler ER, Najjar SS, Rembold CM, Post WS. Use of carotid ultrasound to identify subclinical vascular disease and evaluate cardiovascular disease risk: A consensus statement from the american society of echocardiography carotid intimamedia thickness task force. Endorsed by the society for vascular medicine. J Am Soc Echocardiogr. 2008; 21:93-111. quiz 89-90. [PubMed: 18261694]

10. Peters SA, den Ruijter HM, Bots ML, Moons KG. Improvements in risk stratification for the occurrence of cardiovascular disease by imaging subclinical atherosclerosis: A systematic review. Heart. 2012; 98:177-84. [PubMed: 22095617]

11. Wenger NK. Clinical characteristics of coronary heart disease in women: Emphasis on gender differences. Cardiovasc Res. 2002; 53:558-67. [PubMed: 11861026] 
12. Thurston RC, Chang Y, Derby CA, Bromberger JT, Harlow SD, Janssen I, Matthews KA. Abuse and subclinical cardiovascular disease among midlife women: Findings from the study of women's health across the nation. Stroke. 2014; 45:2246-51. [PubMed: 25034715]

13. Gold E, Colvin A, Avis N, Bromberger J, Greendale G, Powell L, Sternfeld B, Matthews K. Longitudinal analysis of vasomotor symptoms and race/ethnicity across the menopausal transition: Study of women's health across the nation (swan). Am J Public Health. 2006; 96:1226-35. [PubMed: 16735636]

14. Kravitz HM, Zhao X, Bromberger JT, Gold EB, Hall MH, Matthews KA, Sowers MR. Sleep disturbance during the menopausal transition in a multi-ethnic community sample of women. Sleep. 2008; 31:979-90. [PubMed: 18652093]

15. Thurston RC, Bromberger J, Chang Y, Goldbacher E, Brown C, Cyranowski JM, Matthews KA. Childhood abuse or neglect is associated with increased vasomotor symptom reporting among midlife women. Menopause. 2008; 15:16-22. [PubMed: 18257140]

16. Greenfield EA, Lee C, Friedman EL, Springer KW. Childhood abuse as a risk factor for sleep problems in adulthood: Evidence from a u.S. National study. Ann Behav Med. 2011; 42:245-56. [PubMed: 21656087]

17. Thurston RC, Sutton-Tyrrell K, Everson-Rose SA, Hess R, Powell LH, Matthews KA. Hot flashes and carotid intima media thickness among midlife women. Menopause. 2011; 18:352-8. [PubMed: 21242820]

18. Ayas NT, White DP, Manson JE, Stampfer MJ, Speizer FE, Malhotra A, Hu FB. A prospective study of sleep duration and coronary heart disease in women. Arch Intern Med. 2003; 163:205-9. [PubMed: 12546611]

19. Harlow SD, Gass M, Hall JE, Lobo R, Maki P, Rebar RW, Sherman S, Sluss PM, de Villiers TJ. Executive summary of the stages of reproductive aging workshop + 10: Addressing the unfinished agenda of staging reproductive aging. J Clin Endocrinol Metab. 2012; 97:1159-68. [PubMed: 22344196]

20. Bernstein DP, Fink L, Handelsman L, Foote J, Lovejoy M, Wenzel K, Sapareto E, Ruggiero J. Initial reliability and validity of a new retrospective measure of child abuse and neglect. Am J Psychiatry. 1994; 151:1132-6. [PubMed: 8037246]

21. Walker EA, Gelfand A, Katon WJ, Koss MP, Von Korff M, Bernstein D, Russo J. Adult health status of women with histories of childhood abuse and neglect. Am J Med. 1999; 107:332-9. [PubMed: 10527034]

22. Wendelhag I, Gustavsson T, Suurkula M, Berglund G, Wikstrand J. Ultrasound measurement of wall thickness in the carotid artery: Fundamental principles and description of a computerized analysing system. Clin Physiol. 1991; 11:565-77. [PubMed: 1769190]

23. Thompson T, Sutton-Tyrrell K, Wildman RP, Kao A, Fitzgerald SG, Shook B, Tracy RP, Kuller LH, Brockwell S, Manzi S. Progression of carotid intima-media thickness and plaque in women with systemic lupus erythematosus. Arthritis Rheum. 2008; 58:835-42. [PubMed: 18311797]

24. Sutton-Tyrrell K, Wolfson SK Jr, Thompson T, Kelsey SF. Measurement variability in duplex scan assessment of carotid atherosclerosis. Stroke. 1992; 23:215-20. [PubMed: 1561650]

25. Ancoli-Israel S, Cole R, Alessi C, Chambers M, Moorcroft W, Pollak CP. The role of actigraphy in the study of sleep and circadian rhythms. Sleep. 2003; 26:342-92. [PubMed: 12749557]

26. Netzer NC, Stoohs RA, Netzer CM, Clark K, Strohl KP. Using the berlin questionnaire to identify patients at risk for the sleep apnea syndrome. Ann Intern Med. 1999; 131:485-91. [PubMed: 10507956]

27. Freedman RR. Laboratory and ambulatory monitoring of menopausal hot flashes. Psychophysiology. 1989; 26:573-9. [PubMed: 2616704]

28. Thurston RC, Matthews KA, Hernandez J, De La Torre F. Improving the performance of physiologic hot flash measures with support vector machines. Psychophysiology. 2009; 46:28592. [PubMed: 19170952]

29. Carpenter JS, Andrykowski MA, Freedman RR, Munn R. Feasibility and psychometrics of an ambulatory hot flash monitoring device. Menopause. 1999; 6:209-15. [PubMed: 10486790]

30. Radloff LS. The ces-d scale: A self-report depression scale for research in the general population. Appl Psychol Meas. 1977; 1:385-401. 
31. Spielberger, CD. Manual for the state-trait anxiety inventory. Palo Alto: Consulting Psychologists Press; 1983.

32. Friedewald W, Levy R, Fredrickson D. Estimation of the concentration of low density lipoprotein cholesterol in plasma, without use of the preparative ultracentrifuge. Clin Chem. 1972; 18:499_ 502. [PubMed: 4337382]

33. Matthews D, Hosker J, Rudenski A, Naylor B, Teacher D, Turner R. Homeostasis model assessment: Insulin resistance and $\mathrm{b}$ cell function from fasting plasma glucose and insulin concentration in man. Diabetologia. 1985; 28:412-9. [PubMed: 3899825]

34. Heart rate variability: Standards of measurement, physiological interpretation and clinical use. Task force of the european society of cardiology and the north american society of pacing and electrophysiology. Circulation. 1996; 93:1043-65. [PubMed: 8598068]

35. Midei AJ, Matthews KA, Bromberger JT. Childhood abuse is associated with adiposity in midlife women: Possible pathways through trait anger and reproductive hormones. Psychosom Med. 2010; 72:215-23. [PubMed: 20064904]

36. Widom CS, Czaja SJ, Bentley T, Johnson MS. A prospective investigation of physical health outcomes in abused and neglected children: New findings from a 30-year follow-up. Am J Public Health. 2012; 102:1135-44. [PubMed: 22515854]

37. Loucks EB, Almeida ND, Taylor SE, Matthews KA. Childhood family psychosocial environment and coronary heart disease risk. Psychosom Med. 2011; 73:563-71. [PubMed: 21810898]

38. Su S, Jimenez MP, Roberts CT, Loucks EB. The role of adverse childhood experiences in cardiovascular disease risk: A review with emphasis on plausible mechanisms. Curr Cardiol Rep. 2015; 17:88. [PubMed: 26289252]

39. Bertone-Johnson ER, Whitcomb BW, Missmer SA, Karlson EW, Rich-Edwards JW. Inflammation and early-life abuse in women. Am J Prev Med. 2012; 43:611-20. [PubMed: 23159256]

40. Heim C, Newport DJ, Heit S, Graham YP, Wilcox M, Bonsall R, Miller AH, Nemeroff CB. Pituitary-adrenal and autonomic responses to stress in women after sexual and physical abuse in childhood. JAMA. 2000; 284:592-7. [PubMed: 10918705]

41. Girdler SS, Sherwood A, Hinderliter AL, Leserman J, Costello NL, Straneva PA, Pedersen CA, Light KC. Biological correlates of abuse in women with premenstrual dysphoric disorder and healthy controls. Psychosom Med. 2003; 65:849-56. [PubMed: 14508031]

42. Widom C, Shepard R. Accuracy of adult recollections of childhood victimization: Part i. Childhood physical abuse. Psychol Assess. 1996; 8:412-21.

43. Sumner JA, Kubzansky LD, Elkind MS, Roberts AL, Agnew-Blais J, Chen Q, Cerda M, Rexrode KM, Rich-Edwards JW, Spiegelman D, Suglia SF, Rimm EB, Koenen KC. Trauma exposure and posttraumatic stress disorder symptoms predict onset of cardiovascular events in women. Circulation. 2015; 132:251-9. [PubMed: 26124186]

44. Vaccarino V, Goldberg J, Rooks C, Shah AJ, Veledar E, Faber TL, Votaw JR, Forsberg CW, Bremner JD. Post-traumatic stress disorder and incidence of coronary heart disease: A twin study. J Am Coll Cardiol. 2013; 62:970-8. [PubMed: 23810885]

45. Chen E, Miller GE. "Shift-and-persist” strategies: Why low socioeconomic status isn't always bad for health. Perspect Psychol Sci. 2012; 7:135-58. [PubMed: 23144651] 


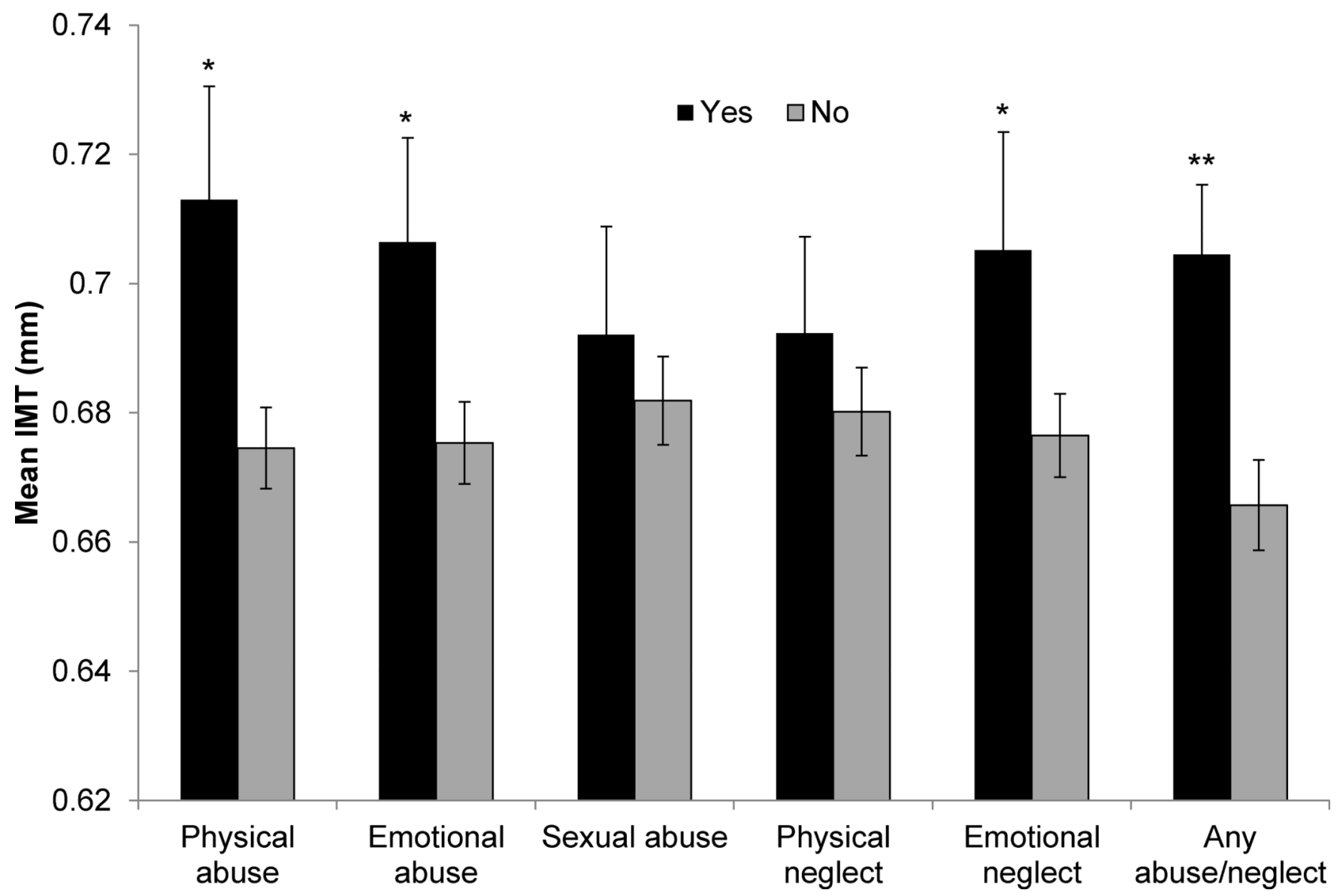

Figure 1. Adjusted mean IMT by abuse or neglect history

$*_{\mathrm{p}}<.05 ; * * \mathrm{p}<.01$; Means adjusted for age, race, education, BMI, SBP, DBP, HOMA, LDL, HDL, triglycerides, shiftwork, medication use (BP-lowering, anti-diabetic, lipid-lowering, antidepressants, anxiolytics, sleep); Error bars represent standard errors 


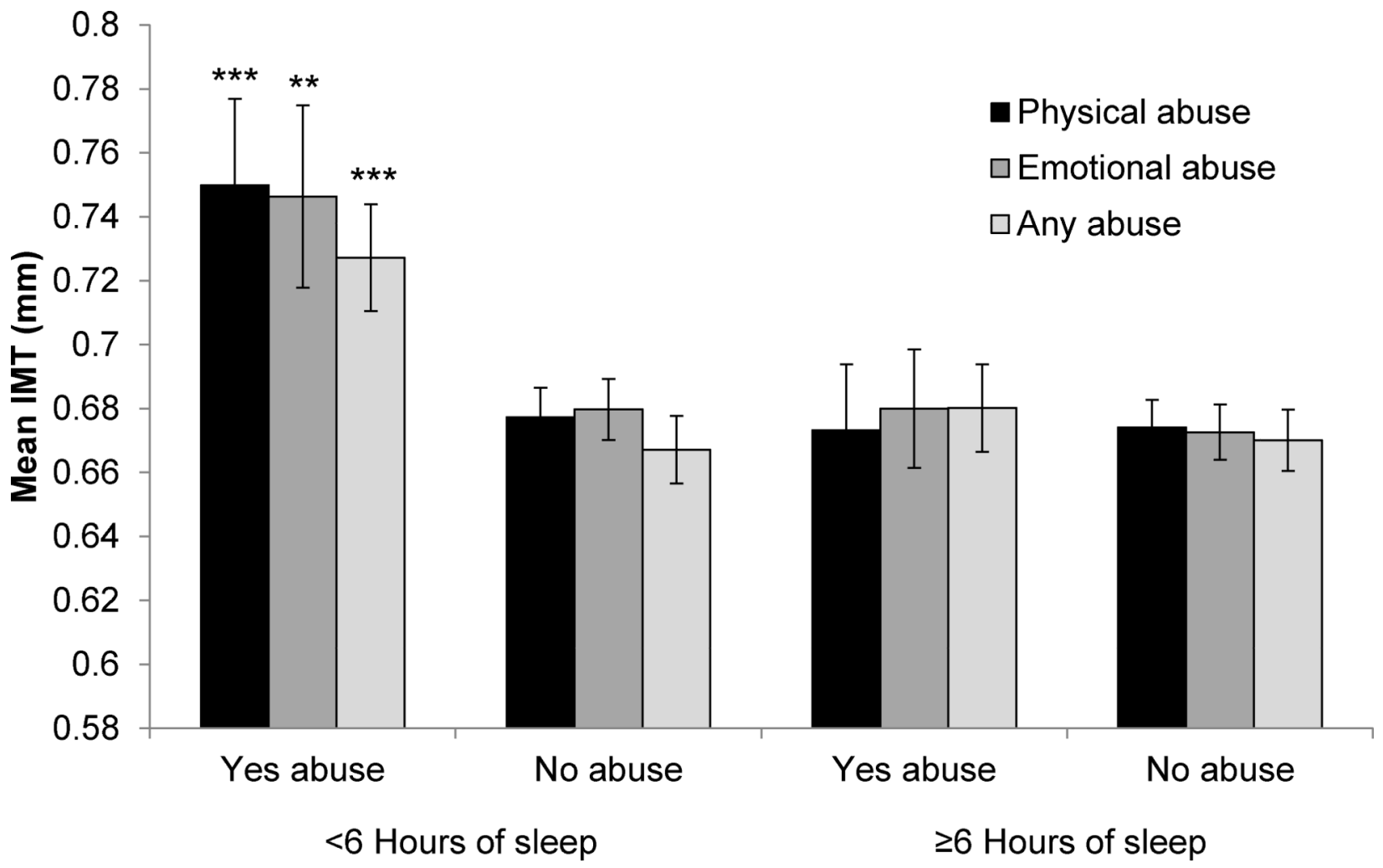

Figure 2. Adjusted mean IMT by abuse or neglect history and sleep time $* \mathrm{p}<.05 ; * * \mathrm{p}<.001 ; * * * \mathrm{p}<.0001$ relative to no abuse $\geq 6$ hours sleep Means adjusted for age, race, education, BMI, SBP, DBP, HOMA, LDL, HDL, triglycerides, shiftwork, medication use (BP-lowering, anti-diabetic, lipid-lowering, antidepressants, anxiolytics, sleep); Error bars represent standard errors Subgroup sample sizes ranged from $\mathrm{N}=27$ ( $<6$ hours sleep/emotional abuse) to $\mathrm{N}=134$ ( $\prec 6$ hours sleep/no physical abuse). Please see Supplemental Digital Content 1 for sample sizes of each subgroup. 


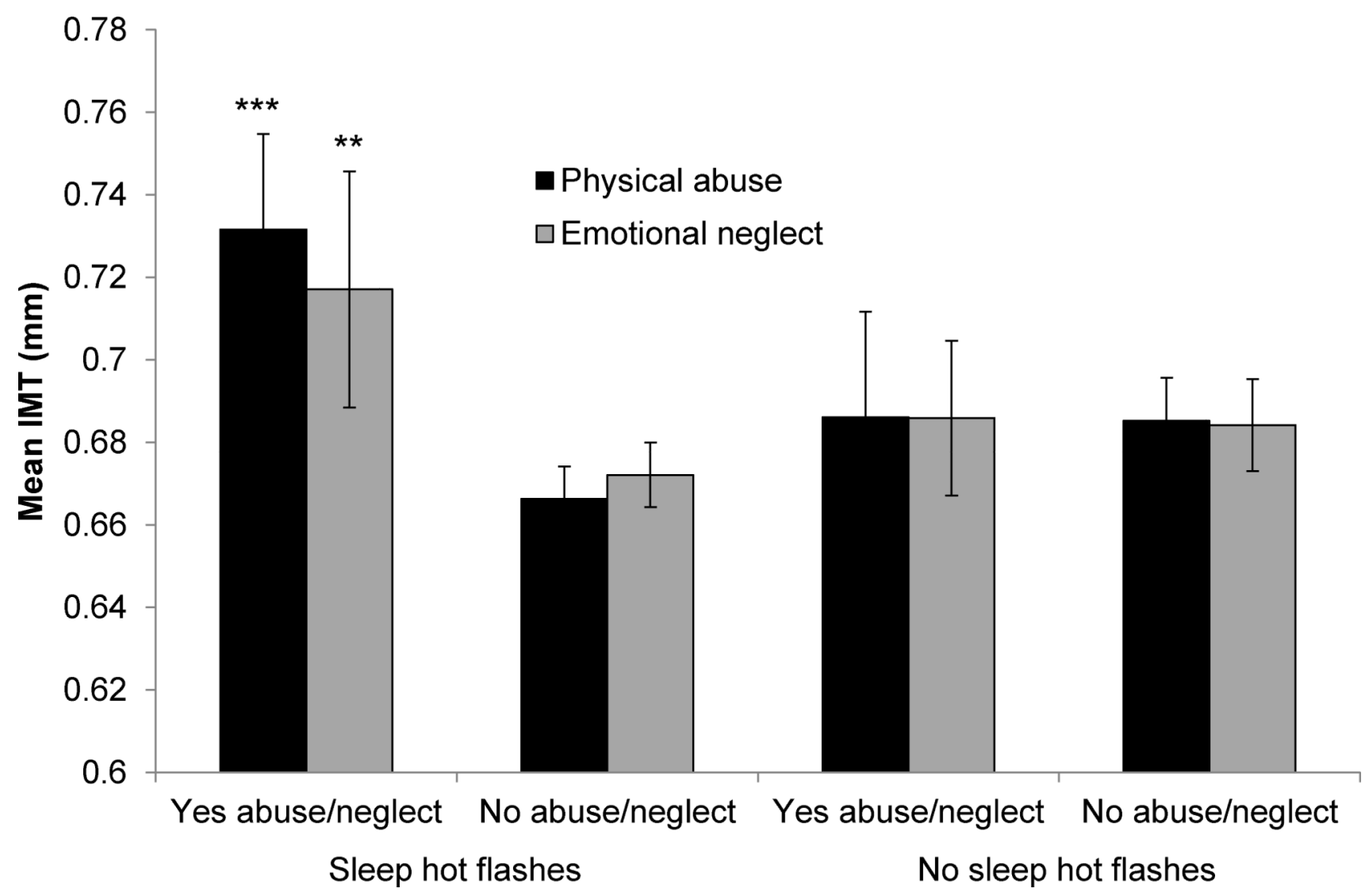

Figure 3. Adjusted mean IMT by abuse or neglect history and sleep hot flashes $* \mathrm{p}<.05, * * \mathrm{p}<.01, * * * \mathrm{p}<.001$, relative to no abuse/neglect sleep hot flashes Means adjusted for age, race, education, BMI, SBP, DBP, HOMA, LDL, HDL, triglycerides, shiftwork, medication use (BP-lowering, anti-diabetic, lipid-lowering, antidepressants, anxiolytics, sleep); Error bars represent standard errors

Subgroup sample sizes ranged from N=22 (no sleep hot flashes/emotional neglect) to N=147 (sleep hot flashes/no emotional neglect). Please see Supplemental Digital Content for sample sizes of each subgroup. 


\section{Table 1}

Participant characteristics by abuse or neglect history

\begin{tabular}{|c|c|c|c|}
\hline & No Abuse/Neglect (N=163) & Any Abuse/Neglect (N=132) & P value \\
\hline Age, M (SD) & $54.28(3.90)$ & $53.68(4.11)$ & .205 \\
\hline Race/ethnicity, N (\%) & & & .008 \\
\hline White & $127(77.91)$ & $86(65.15)$ & \\
\hline Black & $25(15.34)$ & $40(30.30)$ & \\
\hline Other ethnicities & $11(6.75)$ & $6(4.55)$ & \\
\hline BMI, M (SD) & $28.88(6.07)$ & $29.11(7.50)$ & .776 \\
\hline Education, $\mathrm{N}(\%)$ & & & .094 \\
\hline High school/some college & $60(36.81)$ & $65(49.24)$ & \\
\hline College graduate & $51(31.29)$ & $35(26.52)$ & \\
\hline Post-graduate & $52(31.90)$ & $32(24.24)$ & \\
\hline SBP, mm Hg, M (SD) & $117.86(13.54)$ & $121.62(14.65)$ & .023 \\
\hline DBP, mm Hg, M (SD) & $68.92(8.92)$ & $71.49(9.30)$ & .016 \\
\hline Menopause stage, $\mathrm{N}(\%)$, postmenopausal & $136(83.44)$ & $110(83.33)$ & .981 \\
\hline \multicolumn{4}{|l|}{ Hot flashes, M (SD) } \\
\hline Sleep & $2(2)$ & $2(3)$ & .876 \\
\hline Wake & $7(7)$ & $7(7)$ & .479 \\
\hline HOMA, Median (IQR) & $2.13(1.64-3.16)$ & $2.26(1.66-3.16)$ & .781 \\
\hline LDL, mg/dL, M (SD) & $130.18(35.35)$ & $129.75(31.12)$ & .914 \\
\hline $\mathrm{HDL}, \mathrm{mg} / \mathrm{dL}, \mathrm{M}$ (SD) & $62.45(14.97)$ & $63.48(14.87)$ & .555 \\
\hline Triglycerides, mg/dL, Median (IQR) ${ }^{*}$ & $98.00(76-131)$ & $87(70-126.5)$ & .322 \\
\hline HF-HRV, Median (IQR) ${ }^{*}$ & $201.76(116.39-358.69)$ & $188.16(94.45-359.46)$ & .474 \\
\hline IL6, pg/mL, Median (IQR) ${ }^{*}$ & $1.35(.94-2.23)$ & $1.56(1.04-2.31)$ & .189 \\
\hline CRP, pg/mL, Median (IQR) ${ }^{*}$ & $1.44(.68-3.54)$ & $1.28(.68-4.18)$ & .680 \\
\hline Fibrinogen, mg/dL, M (SD) & $348.98(77.62)$ & $343.92(76.27)$ & .575 \\
\hline FVIIc, U/mL, M (SD) & $1.28(.29)$ & $1.28(.30)$ & .951 \\
\hline Willebrand factor antigen, $\mathrm{U} / \mathrm{mL}, \mathrm{M}$ (SD) & $1.34(.50)$ & $1.44(.52)$ & .127 \\
\hline D-Dimer, ng/mL, Median (IQR) ${ }^{*}$ & $225.49(166.01-353.57)$ & $251.42(181.34-396.32)$ & .400 \\
\hline Mean IMT, mm, M (SD) & $.67(.09)$ & $.70(.12)$ & .002 \\
\hline Maximal IMT, mm, M (SD) & $.83(.13)$ & $.88(.18)$ & .004 \\
\hline Adventitial diameter, mm, M (SD) & $6.88(.49)$ & $7.15(.70)$ & .001 \\
\hline Plaque, yes, $\mathrm{N}(\%)$ & $64(39.02)$ & $72(54.14)$ & .009 \\
\hline \multicolumn{4}{|l|}{ Medications, yes, $\mathrm{N}(\%)$} \\
\hline Anti-hypertensive & $25(15.34)$ & $20(15.15)$ & .965 \\
\hline Anti-diabetic & $4(2.54)$ & $5(3.79)$ & .520 \\
\hline Lipid-lowering & $25(15.63)$ & $10(7.69)$ & .068 \\
\hline Anti-depressive/anxiolytic & $6(3.68)$ & $4(3.03)$ & 1.00 \\
\hline Sleep medications & $6(3.68)$ & $7(5.30)$ & .500 \\
\hline
\end{tabular}

Psychosom Med. Author manuscript; available in PMC 2018 May 01. 


\section{Table 2}

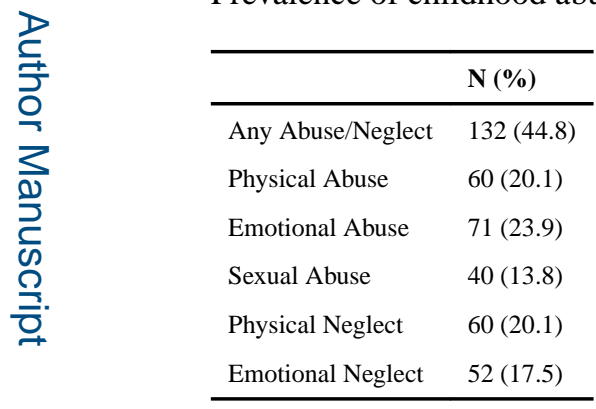

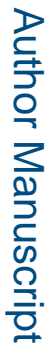

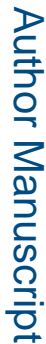

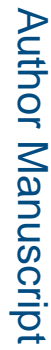

Psychosom Med. Author manuscript; available in PMC 2018 May 01. 
Table 3

Relation between childhood abuse and neglect and carotid intima media thickness (IMT) and plaque

\begin{tabular}{|c|c|c|c|}
\hline & $\begin{array}{l}\text { Mean IMT } \\
\text { B (SE) }\end{array}$ & $\begin{array}{l}\text { Max IMT } \\
\text { B (SE) }\end{array}$ & $\begin{array}{l}\text { Plaque } \\
\text { OR }(95 \% \mathrm{CI})\end{array}$ \\
\hline \multicolumn{4}{|c|}{ Abuse/Neglect Scale Scores ${ }^{*}$} \\
\hline Total Abuse/Neglect & $.110(.034)^{\prime /}$ & $.156(.051)^{/ /}$ & $4.93(.95-25.55)^{* t}$ \\
\hline Physical Abuse & $.018(.007)^{/ /}$ & $.025(.01)^{\xi}$ & $1.30(.95-1.78)$ \\
\hline Emotional Abuse & $.012(.005)^{\xi}$ & $.018(.008)^{\mathcal{\xi}}$ & $1.05(.82-1.36)$ \\
\hline Sexual Abuse & $.003(.006)$ & $.004(.009)$ & $1.13(.85-1.51)$ \\
\hline Physical Neglect & $.012(.007)^{* t}$ & $.017(.01)^{*}$ & $1.24(.91-1.69)$ \\
\hline Emotional Neglect & $.015(.005)^{/ /}$ & $.022(.007)^{/ /}$ & $1.22(.96-1.54)$ \\
\hline \multicolumn{4}{|c|}{ Presence of Abuse/Neglect } \\
\hline Any Abuse/Neglect & $.039(.011)^{/ /}$ & $.051(.016)^{/ /}$ & $1.95(1.15-3.33)^{\mathcal{S}}$ \\
\hline Physical Abuse & $.038(.013)^{/ /}$ & $.054(.02)^{/ l}$ & $2.16(1.14-4.09)^{\mathcal{S}}$ \\
\hline Emotional Abuse & $.031(.013)^{\mathcal{\xi}}$ & $.048(.019)^{\mathcal{S}}$ & $1.27(.69-2.32)$ \\
\hline Sexual Abuse & $.010(.016)$ & $.016(.024)$ & $1.34(.65-2.78)$ \\
\hline Physical Neglect & $.012(.014)$ & $.014(.021)$ & $1.83(.96-3.47)^{* t}$ \\
\hline Emotional Neglect & $.029(.014)^{\xi}$ & $.044(.021)^{\mathcal{S}}$ & $1.21(.63-2.34)$ \\
\hline
\end{tabular}

* Scale scores transformed as 1-1/CTQ score, beta represents every .05 increment increase in scale (approximately 1 SD)

CTQ clinical cutpoints: emotional abuse $=10$, physical abuse $=8$, sexual abuse $=8$, emotional neglect $=15$, physical neglect $=8$; any abuse or neglect=scoring at or above the clinical threshold on any one subscale

Covariates: age, race, education, BMI, SBP, DBP, HOMA, LDL, HDL, triglycerides, shiftwork, medication use (BP-lowering, anti-diabetic, lipidlowering, antidepressants, anxiolytics, sleep)

${ }^{*} \mathrm{p}<.10$

$\xi_{\mathrm{p}<.05}$

$/ \mathrm{p}<.01$ 